Eurasian Journal of Educational Research 77 (2018) 65-80

Eurasian Journal of Educational Research
www.ejer.com.tr

\title{
Accuracy Order of English Grammatical Morphemes of Saudi EFL Learners*
}

Abuelgasim Sabah Elsaid MOHAMMED ${ }^{1}$, Abdulaziz Bashir SANOSI ${ }^{2}$

\begin{tabular}{|c|c|}
\hline ARTICLE INFO & A B S T R A C T \\
\hline $\begin{array}{l}\text { Article History: } \\
\text { Received: } 18 \text { Jan. } 2018 \\
\text { Received in revised form: } 1 \text { May. } 2018 \\
\text { Accepted: } 5 \text { Sept. } 2018 \\
\text { DOI: 10.14689/ejer.2018.77.4 } \\
\text { Keywords } \\
\text { Second Language Acquisition, Morpheme } \\
\text { Acquisition, Natural Order Hypothesis }\end{array}$ & $\begin{array}{l}\text { Purpose: This paper investigates the accuracy order } \\
\text { of grammatical morphemes followed by Saudi EFL } \\
\text { learners. The major aim of the research was to reveal } \\
\text { the pattern of grammatical morpheme acquisition of } \\
\text { the participants, and to compare it against the } \\
\text { Natural Order Hypothesis (NOH) as stated by } \\
\text { Krashen (1977). The different factors that affected the } \\
\text { generated order were also discussed. Research } \\
\text { Methods: The present research adopted a descriptive } \\
\text { quantitative design. Three groups of male and female } \\
\text { students ( } n=258 \text { ) participated in the study. The } \\
\text { participants were selected randomly from public } \\
\text { schools and university colleges. They responded to a } \\
\text { grammar elicitation task designed to test their } \\
\text { accuracy of using grammatical morphemes. }\end{array}$ \\
\hline
\end{tabular}

Pica's (1983) TLU method was used to assess the participants' performance. Findings: It was found that Saudi EFL learners developed the accuracy of using grammatical morphemes in a similar sequence regardless of their educational stages. Although this sequence was fixed, there seemed to be a clear effect of the educational stage upon the quality of their usage. The generated accuracy order was found to be different from the NOH. This result suggested that the participants' first language (L1) affected the accuracy order of grammatical morphemes. Implications for research and practice: The findings of the study suggested that course book lesson plans should be designed according to the generated order to facilitate grammatical morpheme acquisition. Further research that will utilize a bigger size of samples is also required to confirm the generated order.

(C) 2018 Ani Publishing Ltd. All rights reserved

\footnotetext{
* This research was supported by the Deanship of Scientific Research at Prince Sattam Bin Abdulaziz University, Saudi Arabia, under the research project \# 2017/2/7702.

${ }^{1}$ Department of English language, Prince Sattam Bin Abdulaziz University, Howtat Bani Tamim, Saudi Arabia. ab.ibrahim@psau.edu.sa. ORCID 0000-0001-9791-0905.

2 Corresponding Author: Department of English language, Prince Sattam Bin Abdulaziz University, Howta Bani Tamim, Saudi Arabia. a.assanosi@psau.edu.sa. ORCID 0000-0003-3447-2818
} 


\section{Introduction}

One of the famous approaches that attempted to explain language acquisition is the Innatist view, which was suggested by Noam Chomsky and his followers in the late 1950s. The main argument that led to the emergence of the Innatist theory was that language learners learn more than the input they are exposed to. It was argued that learners, in fact, benefit from something that, as White (2003) described, goes far beyond the input. This argument, which is known as the Poverty of Stimulus Theory, was originally presented by Chomsky (1965) who claimed that the innate knowledge of the language is traced back to a Language Acquisition Device (LAD) that is possessed by every child regardless of their first language (L1). Correspondingly, children acquire their L1 system by manipulating a universal grammar (UG) system that fits every natural language. As a crucial part of linguistic structure, morphemes are believed to be acquired in a specific order. However, no final answer has been presented to the question of whether this order is universal or L1 specific. Answering such a question would be significant as it might provide insightful pedagogical implications on grammar instruction and language acquisition.

In accordance with the Innatist theory, many questions regarding the nature of learner language have been posed. Researchers have shown a considerable interest specifically to the continuum that language learners follow. Children, it was assumed, utilize their built-in syllabus, to acquire linguistic items in a unified sequence. This built-in syllabus, as it was termed by Corder (1967), controls the developmental patterns with which children process their first language (L1). Although the focus of these studies was to justify errors that children committed while they produced their language, as well as to depict these errors as a natural consequence of the developmental stages; it was nevertheless insightful to the subsequent research on the developmental sequence of acquisition.

As far as the second language (L2) is concerned, other questions emerged, the most prominent of which was about whether this built-in capacity was also used by adult learners. It was claimed that all humans possess the instinctive ability to process language, and it keeps working until a late age in life. It can be inferred from this claim that L2 learners also follow a predetermined order of acquisition; however, researchers did not take these views for granted. Rather, there was a sensible argument based on the grounds that L1 acquisition is different from SLA. This argument revolves around the fact that, in contrast to SLA, L1 acquisition is inevitable, represents part of natural development, requires no motivation, and starts with no previous linguistic knowledge. However, it was believed that "the strategies adopted by the learners of a second language are substantially the same as those by which a first language is acquired" (Corder 1967, p. 165). The similarity of these strategies, it was believed, results in similar developmental patterns, and as a result, this hypothesis underwent continuous testing throughout the subsequent decades.

In this regard, researchers have classified two types of developmental patterns in SLA. The first is what is termed by VanPatten and Benati (2010), as (Stage-like Development) or (Sequence of Acquisition) by (Ellis, 2010). This type of sequence 
addresses the steps L2 learners take to acquire an entire linguistic feature. It was found that there are definite stages that are followed by L2 learners in order to acquire specific features such as question formation, word order, and negation. Research on this concept proved that most L2 learners follow these patterns regardless of their learning settings.

An example of the developmental patterns in SLA is what Ellis (2010) termed (Order of Acquisition) and was referred to as (Ordered Development) by other researchers such as VanPatten and Benati (2010). This was concerned with the development of different linguistic features over time. The primary concern of most studies that investigate this type of development is the acquisition of grammatical morphemes of a language. Studies of this type appeared relatively early and yielded interesting results that enriched the language acquisition literature.

\section{Morpheme Acquisition Order (MAO)}

Early investigations of morpheme acquisition revealed that "second language learning was predicted to consist of the acquisition of rules and structures of target language in a gradual process over an extended period of time" (Mansouri, 2008, p. 2). Justifications of these findings were not definitive and remain, as many phenomena of SLA, a matter of speculation. One of the first linguistic elements to be tested for their gradual acquisition was the morphemic system of languages. In the following sections, MAO studies are discussed along with the major perception of MAO and its related concepts.

\section{L1 Morpheme Studies}

The first morpheme studies dealt with first language acquisition. Several studies were conducted to investigate the sequence with which children acquired their mother tongue. Brown (1973) studied the development of 14 English grammatical morpheme acquisitions by three English-speaking children. He monitored their progress longitudinally and found that the three children had followed an order which started with present progressive [-ing], and went through 13 morphemes and finished with the contradictable auxiliary morpheme.

Shortly after the Brown (1973) findings, de Villiers and de Villiers (1973) conducted a cross-sectional study to investigate the order of acquisition of the same 14 grammatical morphemes by 21 children. They found that the subjects followed the same order revealed earlier by Brown (1973). These two studies provided to be powerful support for the hypothesis of universal predictable MAO.

Generally speaking, researchers believe that "among first language learners, the existence of developmental sequences may not seem surprising because their language learning is partly tied to their cognitive development" (Lightbown \& Spada, 2013, p. 245). Conversely, the developmental patterns of L2 learners entail much argument since the existing linguistic system may interfere with the L2 and influence the developmental sequences. 


\section{L2 Morpheme Studies}

In the 1970s, many studies that dealt with MAO were conducted. Dulay and Burt carried out three studies (1972, 1973, \& 1974) which investigated the universal regularities in child SLA. They concluded that "regardless of first language background, children reconstruct English syntax in similar ways" (Dulay \& Burt, 1974, p. 37). After applying three different methods (i.e., Group Score Method, Group Mean Method, and Syntax Acquisition Index (SAI) method), the rank order they found was similar among all children whose L1 were different (i.e., Spanish, Chinese, Japanese, and Norwegian). These results were inspiring to almost all subsequent studies especially with reference to the different linguistic backgrounds of the subjects and the variety of the methods followed. Table 1 below presents the rank order obtained via one of those pioneer studies.

\section{Table 1}

L2 Rank Order (Sequences) Obtained

\begin{tabular}{|c|c|c|}
\hline Group Score Method & Group Means Method & SAI Method \\
\hline 1 case & 1 case & 1 case \\
\hline 2 article & 2 article & 2 copula \\
\hline 3 copula & $\begin{array}{c}3.5 \text { \{copula }\} \\
\text { \{ing }\}\end{array}$ & $\begin{array}{c}3.5 \text { \{article }\} \\
\{\text {-ing }\}\end{array}$ \\
\hline 4 -ing & 5 plural & 5 auxiliary \\
\hline 5 plural & 6 auxiliary & 6 plural \\
\hline 6 auxiliary & 7 past-reg & $\begin{array}{l}7.5 \text { \{past irregular\} } \\
\text { \{possessive\} }\end{array}$ \\
\hline 7 past-reg & $\begin{array}{l}\text { 8.5\{past-irregular\} } \\
\{\text { possessive }\}\end{array}$ & 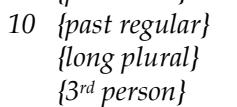 \\
\hline 8 past-irreg. & 10 long plural & \\
\hline 9 long plural & $113 r d$ person & \\
\hline 10 possessive & & \\
\hline 11 3rd person & & \\
\hline
\end{tabular}

(Dulay \& Burt, 1974, p. 51)

Likewise, Bailey, Madden and Krashen (1974) investigated the order of acquisition of grammatical morphemes followed by EFL learners of different backgrounds. The focus of the study was on adult learners who were divided into two groups: Spanish L1 and non-Spanish L1, the results are tabulated in table 2.

Table 2

Morpheme Acquisition Order of Adult Learners

\begin{tabular}{ll}
\hline Spanish L1 group & Non-Spanish L1 Group \\
\hline 1 article a, the & 1-present progressive -ing \\
2 present progressive -ing & 2-contractible copula \\
3 plural -s & 3-past irregular \\
4 contractible copula & 4 - plural -s \\
5 contractible auxiliary & 5 - contractible auxiliary \\
6 past irregular & 6 - articles a, the \\
7 3rd person & 7 -3rd person singular \\
8 possessive-'s & 8 -possessive-'s \\
\hline
\end{tabular}

(Bailey et al., 1974, p. 239) 
These results led to a common belief about the supposition of the regular order of morpheme acquisition. The hypothesis was then standardised as Krashen (1977) posited it as one construct of his monitor model and termed it as the Natural Order Hypothesis.

\section{The Natural Order Hypothesis (NOH)}

According to the $\mathrm{NOH}$, "acquirers of a given language tend to acquire certain grammatical structures early and others later" (Krashen, 1982, p. 12). Krashen concluded the results of many contemporary English morpheme order studies at that time, including his own, (Krashen (1977), presented the average acquisition order of English grammatical morphemes for L2 learners as seen in Figure 1.

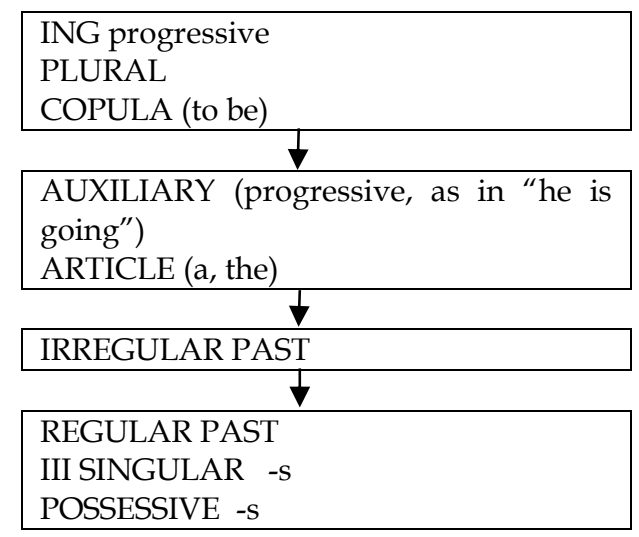

Figure 1. Average Order of Acquisition of Grammatical Morphemes for English as a Second Language (Children and Adults)

Source: Krashen, 1982, p. 13.

As one notes, Krashen (1982) put morphemes in boxes. He claimed that morphemes in the same box are normally acquired before those in the next box. However, no claims were made about ordering relations for morphemes in the same box. In this way, this order seems to be more flexible and yields similar results in future studies.

Comparing this acquisition order to that of Dulay and Burt (1974), it is apparent that although there are some differences at first glance, there is also a considerable similarity in the general pattern of the acquisition order. It was evident that Dulay and Burt (1974) studied 12 grammatical morphemes while Krashen's pattern consists of only nine. This difference is likely to cause some variations in order. If we exclude the three extra morphemes in Dulay and Burt's order and compare the other to Krashen's order, the results will look like what appears in Table 3. 
Table 3

A Comparison Between Acquisition Orders by Dulay \& Burt (1973) and Krashen (1977)

\begin{tabular}{lc}
\hline \multicolumn{1}{c}{ Dulay and Burt } & Stephen Krashen \\
\hline 1- article & progressive -ing \\
2- copula & plural -s \\
3- progressive - ing & copula \\
4- plural -s & Auxiliary \\
5- auxiliary & Article \\
6- regular past & irregular past \\
7- irregular past & regular past \\
8- possessive -s & 3rd Person -s possessive -s \\
9- 3rd Person -s & \\
\hline
\end{tabular}

Considering the fact that the order of single morphemes in one box in Krashen's order is not final, it is apparent that 5 out of 9 morphemes shared the same rank. Additionally, even the differences between the other morphemes were slight (i.e., regular and irregular past).

The $(\mathrm{NOH})$ remains an inspiring tool that is frequently used by Second Language Acquisition (SLA) researchers to assess the development of learners' competence in syntax and grammar. Despite that, 44 years of research literature has shown no consensus on some pivotal components of the hypothesis, for example, as to whether the order is truly universal and impervious to other external factors such as L1 background, the linguistic quality of the morphemes or the setting of language learning. Ultimately, in recent years, research has provided ample support for the assertion that although there is some kind of consistency in the acquisition of grammatical morphemes by EFL learners, special attention should be paid to important influencing factors that may govern this order. The effect of L1 on morpheme acquisition is the most important of these factors.

Effect of L1 on MAO

The early morpheme studies claimed that order of acquisition was not affected by the learners L1. Much of the current debates, notwithstanding; revolves around the effect of L1 on order of acquisition. For some researchers, the influence of L1 over morpheme acquisition order might be overlooked or neglected because "many morpheme studies have lumped different L1 groups together" (Luk \& Shirai, 2009, p. 725). Analogously, Murakami and Alexopoulou (2016, p. 28) argue that "morphemes encoding language-specific concepts (e.g., definiteness) are more severely affected by L1 than morphemes encoding universal-specific concepts." For this reason, it was noted that English articles are the most rank-changing morphemes across different orders of acquisition. By the same token, many other research studies proved prominent influence of L1 over the order of morpheme acquisition (Izumi \& Isahara, 2004; Khor, 2012; Schenk \& Choi, 2013; and Seog, 2015) to name a few.

Based on the noticeable influence of L1 on MAO which was apparent in the previous studies, the present research adopted the concept that there are some 
disparities of morpheme order that can be traced back to L1 interference. These deviations, although slight, show patterns of consistency within learners of the same native language. Accordingly, the researchers hypothesised that order of morpheme acquisition of Saudi learners, and inevitably all Arabic-L1 learners, is different from the proposed $\mathrm{NOH}$.

\section{Acquisition Order vs. Accuracy Order:}

The concepts of acquisition order and accuracy order have been used interchangeably in the morpheme acquisition literature; however, certain theoretical and methodological differences can be noted between the two concepts. Initially, researchers used the term acquisition order. The acquisition-learning hypothesis was dominant at that time, so it was the norm to use the term (acquisition), yet other first morpheme studies adopted the term accuracy order. This was based "on the grounds that the more accurately a morpheme was used, the earlier it must have been acquired" (Ellis, 2010, p. 91).

An important methodological criterion to consider; however, was that acquisition, as defined by the monitor model of Krashen (1977), cannot be investigated at a point in time or cross-sectionally. Rather, "acquisition orders are concerned with when learners begin to do things correctly most of the time. The standard measure is 90 per cent accurate" (VanPatten \& Benati, 2010, p. 28). Measuring this cannot be achieved except by adopting a longitudinal method. Accuracy order, on the other hand, can be measured at one point in time and then accounted for as the acquisition order depending on the above-mentioned considerations.

Accordingly, many modern studies have accepted this view and termed the process as (acquisition order) although they have adopted cross-sectional methods. Examples of these studies are Behajat \& Sadighi, 2011; Dabove, 2014; Ibrahim eth al., 2013; and Murakami \& Alexopoulou, 2016. Other studies, nevertheless, committed to the methodological standards and termed the process as accuracy order (Barrot, 2009; Kharrati et al., 2015; Murakami, 2013; and Seog, 2015).

Throughout this research, the two terms have been used interchangeably; however, because this study is cross-sectional in nature, the term (accuracy order) is used when the context requires defining the process studied in the current research.

\section{Purpose of the Study}

This study investigated the morpheme accuracy order followed by Saudi Arabian EFL learners. To achieve this, this research tested the following two null hypotheses:

$\mathrm{H}_{0}$ 1. Saudi EFL learners develop the acquisition of English grammatical morphemes in a similar order regardless of their age and learning setting $\mathrm{NOH}$.

$\mathrm{H}_{0}$ 2: There is no relation between the Saudi MAO and the orders stated by the 
Method

Research Design

This study employed a descriptive quantitative approach to check its variables. Seliger \& Shohamy (2000, p. 117) stated that "a descriptive case study might provide an in-depth linguistic analysis of the development of some aspects of grammatical ability with a second language learner"; moreover, it was carried out cross-sectionally. Although the first morpheme studies were conducted longitudinally, the recent trends applied by most applied linguistic researchers have been to apply the cross-sectional method in investigating the different applied linguistics issues. The reason for this was that longitudinal design is impractical or not economical and may result in losing some or most of the participants. Moreover, Dornyei $(2007$, p. 89) noted that "in crosssectional study, we are less exposed to the detrimental impact of unforeseen external events that are beyond our control". However, researchers agreed that when using cross-sectional design in morpheme studies, what is actually measured is the accuracy order that can be considered an indication of acquisition order.

\section{Research Sample}

Three groups of Saudi Arabian EFL learners cooperatively participated in the current study. The total number of participants in study sample was [258] male and female students who were selected randomly from four schools and two university colleges at Houtat Bani Tamim in the central region of Saudi Arabia. They represented three educational stages and were distributed into three groups. Group A was incorporated of 85 intermediate school students, and Group B was composed of 84 secondary school students. Group C included male and female college students.

\section{Research Instrument}

The data of this research were collected via a grammaticality judgement test of 11 statements (see Appendix A for a copy of the test). Each of the statements included one or more grammatical mistakes pertaining to grammatical morphemes. The same test was used to collect data from the three groups of participants who were asked to rewrite the statements and correct the grammatical mistakes taking advantages of the adjacent constituents i.e. the linguistic context of each statement.

The test was designed in the Suppliance in Obligatory Context (SOC) method, as explained by Brown (1973). When using such a method, the linguistic context of the statement provides an obligatory context that requires only one possible answer. The researchers used different structural and semantic clues to create the obligatory context for each morpheme. For example, adverbs of frequency were used to prompt using present simple morpheme $\{-S\}$ and distinctive or repeatedly-mentioned nouns were inserted to indicate using definite articles. The objective of using such a method was to make the test more structured and systematic and to avoid diversified answers that would make scoring inaccurate. Six grammatical morphemes were targeted via the test: three of them were noun-related morphemes and three were verb-related. The noun-related morphemes were plural $\{-S\}$, possessive $\left\{{ }^{\prime} S\right\} /\left\{-S^{\prime}\right\}$, and the articles; 
whereas, the verb-related morphemes were progressive $\{$-ing $\}$, regular past $\{-E d\}$ and third person singular $\{-S\}$ (See appendix A for the test). The selected grammatical morphemes were present in the seven major L1 and L2 morpheme studies according to Dabove (2014).

The accuracy of use of each of the six morphemes was assessed 3 times in different statements of the test. Given that the total number of the test statements was only eleven, some statements assessed the use of two or three morphemes simultaneously.

\section{Validity and Reliability}

To determine the content validity of the test, the researchers distributed the targeted morphemes among the test items evenly. After that, the test was presented to a jury of seven academics in the fields of applied linguistics, ELT, and TEFL to analyse its structure and decide if it provided a proper representation of the content it aimed to measure. All of the members were cooperative and they replied with valuable suggestions and advice that were used to edit the final copy of the test.

After conducting the validity measures, the researchers carried out a pilot study which incorporated 87 EFL students representing two different educational stages. 43 of the participants were secondary-school students while the other 44 were college students. The first version of the test was responded to by the participants. After the scoring process, the researchers revised the test and made some slight changes related to possible occasions where students would perform avoidance or compensation strategies and hence provide unrequired responses. The pilot study scores were then used to compute the Cronbach Alpha Coefficient of internal consistency to check the reliability of the test. The generated reliability value was (.89). Given that the optimal reliability coefficient normally ranges between .70 and .80, Dornyei (2007) and Seliger and Shohamy (2000), the reliability of the instrument from the present study seemed to be convincing to the researchers. Therefore, the final version of the test was distributed to collect the research data.

\section{Procedures}

The researchers distributed 300 copies of the test to the selected schools and colleges. The test was administered by the actual teachers of the participants in normal classes. A short guide that described the test and its mechanism was handed out to the teachers who administered the test. After completing the process, the researchers collected 274 copies which represented $91 \%$ of the distributed ones. Later, the researchers excluded 16 copies because they were incomplete. This accounted for the final body of data composed of 258 test copies.

\section{Data Analysis}

The test statements were scored in a method that is capable of providing sufficient data that could be processed by the Target-like Use (TLU) formula from Pica (1980). According to this method, the overall students' performance should be assessed. In this way, the scoring took into account the correct production of morphemes and the cases of overgeneralization or incorrect morpheme suppliance. Therefore, a score of 1 
is given for any correct response whereas another score of $1^{*}$ is given for the incorrect suppliance of morphemes. For example, when the subjects provided an $\{-\mathrm{ING}\}$ morpheme for a situation where a third person singular $\{-S\}$ was required, this overuse was marked $\left(1^{*}\right)$ to indicate that the subjects have knowledge of the $\{-\mathrm{ING}\}$ morpheme but their use lacked accuracy. Finally, the scores of both correct usage and overgeneralization were tabulated in independent columns at the end of the test sheet to be counted and analysed. To maintain rater reliability, both researchers scored all of the test papers separately after agreeing on the above criteria. There was complete agreement between the two raters on almost all of the participants' scores. In the few cases, where the scores were different, they discussed the situation in detail, and then the paper was re-evaluated accordingly.

The researchers adopted accuracy usage of morphemes as a tool to measure acquisition order. This has been a common method in nearly all recent cross-sectional morpheme studies since actual acquisition can only be investigated longitudinally (Barrot, 2009; Ellis, 2010; Lightbown and Spada, 2013; and Murakami; 2016). To achieve this, the researchers utilized the (TLU) method (Pica 1983). TLU is computed by a formula which reduces the score of the subjects each time s/he uses a morpheme incorrectly. The TLU formula is shown in Figure 2.

\section{Number of Correct Suppliance Number of Obligatory Contexts + Number of Overgeneralization Errors $\times 100$}

Figure 2. Pica's (1983) TLU Formula

When applying this formula, overgeneralization errors are penalized effectively. Accordingly, TLU is considered more accurate and fairer in measuring morpheme accuracy and acquisition (Ibrahim et al., 2013; Kharrati et al., 2015; Lightbown \& Spada, 2013; Seog, 2015; and Murkami, 2016).

To investigate the correlation between the rank-order of the present research and the previously-generated orders, for example, NOH by Krashen (1977), the researchers computed a Spearman rank-order correlation. They employed SPSS software to compute the correlation.

\section{Results}

The TLU scores achieved by members of each group were computed. The mean TLU scores for each group are presented in Table 4 . 
Abuelgasim Sabah Elsaid MOHAMMED-Abdulaziz Bashir SANOSI Eurasian Journal of Educational Research 77 (2018) 65-80

\section{Table 4}

The Mean TLU Scores of Grammatical Morphemes Across The Three Groups

\begin{tabular}{llll}
\hline Morpheme & & \multicolumn{2}{c}{ Mean TLU Scores } \\
& Group A & Group B & Group C \\
\hline Plural $\{-$ S $\}$ & 55.7 & 68.5 & 74.6 \\
Past $\{$-ed $\}$ & 48.2 & 60.9 & 66.1 \\
Progressive $\{$-ing $\}$ & 39.1 & 52.6 & 59.5 \\
3rd person $\{-S\}$ & 33.8 & 42.2 & 48.5 \\
Possessive $\{-S\}$ & 23.6 & 33.5 & 37.7 \\
Articles & 9.4 & 16.8 & 21.1 \\
\hline
\end{tabular}

According to these findings, the first hypothesis of this research $\left(\mathrm{H}_{0} 1\right)$ was approved. The research sample displayed a morpheme acquisition pattern which is presented in Figure 3.

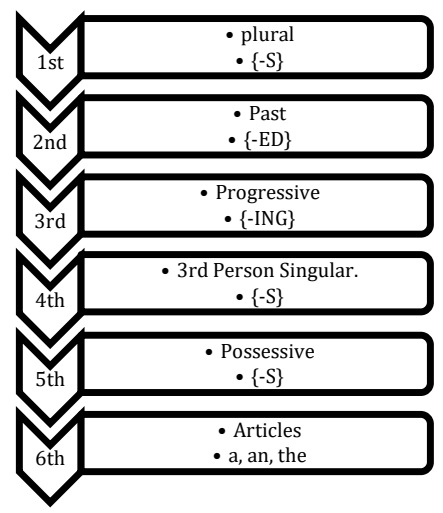

Figure 3. Saudi EFL Learners MAO

This order was fixed across the three groups of participants; therefore, it was taken as a model of Saudi EFL Learners grammatical morpheme acquisition.

The relation between the generated MAO and Krashen (1977) was analysed and the results from the Spearman correlation are displayed in Table 5. 


\section{Table 5}

Spearman's Rho Correlation Coefficient (Tow-Tailed) of Accuracy Orders: Comparison of The Present Study with The NOH.

\begin{tabular}{lcc}
\hline & The present study & Sig. (2-tailed) \\
\hline Krashen_NOH & .429 & .397 \\
\hline
\end{tabular}

These findings imply that there was no correlation between the $\mathrm{NOH}$ and the generated Saudi EFL MAO. This was evident in the low correlation coefficient (0.42). Accordingly, the second hypothesis of the research $\left(\mathrm{H}_{0} 2\right)$ was accepted. The research sample displayed the morpheme acquisition pattern presented in Figure 3.

\section{Discussion, Conclusion and Recommendations}

According to the results of this research, the participants developed the acquisition of English grammatical morphemes in a specific order regardless of their educational stages. The highest TLU scores achieved by members of the three groups pertained to the plural $\{-S\}$ morpheme while the lowest TLU score was related to the articles $(a$, an, the). It can be inferred from these findings that Saudi EFL learners acquired plural $\{-S\}$ morpheme earlier than the other morphemes. This finding is based on the assumption that accuracy equals acquisition i.e. the more accurately a morpheme is used the earlier it is acquired). This assumption was adopted in almost all of the cross-sectional MAO studies, as it was difficult to longitudinally monitor morpheme acquisition.

The second rank of the study MAO was occupied by the regular past morpheme $\{-$ ed followed by progressive $\{$-ing $\}$, third person singular $\{-S\}$, and possessive $\{-S\}$. There was a considerable difference between the TLU scores of each of these morphemes across the three groups. The last rank, however, was occupied by the articles ( $\mathrm{a}$, an, the). The sharp difference between the TLU scores of articles and the other morphemes made it the most confirmed rank of the MAO. The performance of the three groups regarding articles was poor with an average TLU score of only $(15.7 \%)$ which clearly indicated a low-level competence of all the participants regarding articles.

The findings, which were yielded by hypothesis 1 of this research, conformed to the results from many previous studies. Barrot (2009), Ibrahim et al., (2011), Khor (2012), and Kharrati et al., (2015) found a consistency in the MAO patterns exhibited by their subjects. The results also coped with the findings of the first studies that inspired the NOH. Since the studies of Dulay and Burt $(1973,1974)$ and Bailey et al., (1974), there has been a kind of agreement that MAO is universal to all learners. This view seems too general for contemporary researchers who are sceptical regarding the element of universality; however, they do not often reject the systemic nature of morpheme acquisition. Luk and Shirai (2009), for example, accept the notion of universal aspects of morpheme acquisition, but they bound this to learners with 
similar L1 backgrounds. Many other contemporary researchers follow these views and suggest specific MAO patterns for different groups of EFL learners.

To investigate these different concepts, the researchers analysed the relationship between $\mathrm{NOH}$ and the generated order. It was found that there was no correlation between the two. All the studied morphemes occupied different ranks in the two orders. However, the most considerable differences were between the ranks of articles, progressive $\{-\mathrm{ING}\}$ and past $\{-\mathrm{ED}\}$. Bearing in mind that the participants' L1 (Arabic) has different equivalent morphemes to the plural $\{-S\}$ and past $\{-E D\}$, it can be suggested that MAO is determined by the participants L1. The difference of the article systems of Arabic and English, that is the absence of indefinite articles in Arabic,) was further evidence to support this claim since articles occupied the latest rank of the EFL learners' MAO in this present study.

These results also coordinated with the findings of some previous studies that found deviations from NOH. Seog (2015), for example, found complete differences between Korean MAO and $\mathrm{NOH}$. She confirmed the previous results that had been generated by an earlier study by Kim (2001) of Korean learners. The findings of Dabove (2014), also reported deviations from $\mathrm{NOH}$ although some similarities to other previous rank orders were witnessed. These findings then proved that there might be deviations from $\mathrm{NOH}$ by learners of different L1 backgrounds that are caused by various factors.

The findings of the present study support the claim that EFL learners of the same L1 background and learning setting acquire morphemes in a fixed predetermined order. This order is not affected by the learning setting (e.g., age and exposure to English); however, the quality of morpheme usage correlated positively to the educational stage of the learners. Moreover, although this pattern of acquisition was systematic and fixed, it was not universal. There was a clear effect of the learners' L1 that seemed to shape the order of each learners group with similar L1 backgrounds. These findings may provide important implications to future teachers and curriculum designers.

Although it was claimed that instruction may not be capable of altering the acquisition sequence of different linguistic elements, it would be fruitful for curriculum designers and Saudi EFL teachers to be aware of the systematic nature of grammatical morpheme acquisition and the order in which EFL learners acquire grammatical morphemes. Based on the results of this study, it is recommended that course designers and Saudi EFL teachers utilize this MAO pattern to shape their course plans. Accordingly, grammar lessons should be sequenced according to the generated order in order to help students acquire grammatical morphemes, and more focus should be placed on those morphemes that have no counterparts in Arabic and hence occupy a late rank in the order. Further studies employing larger sample sizes are also needed in order to clearly confirm the order revealed by this study. 


\section{References}

Bailey, N., Madden, C., \& Krashen, S. (1974). Is there a "natural sequence" in adult second language learning? Language Learning, 24, 235-243.

Barrot, J. (2010). Accuracy order of selected grammatical morphemes in the monitored written Compositions of Filipino adult language. Philippine ESL Journal, 4 , $45-65$.

Behajat, F. \& Sadighi, F. (2011). The acquisition of English grammatical morpheme: A case of Iranian EFL learners. The Modern Journal of Applied Linguistics, 3(2), 105-123.

Brown, R. (1973). A First language: The early stages. Cambridge, Massachusetts, Harvard University Press.

Corder, P. (1967). The significance of learners' errors. International Review of Applied Linguistics, 5, 161-171.

Dabove, A. (2014). A study of morpheme acquisition in an EFL corpus of L1 Spanish - L2 English: Some pedagogical implications (Master's thesis). Retrieved from digibug.ugr.es/.../1/AGUSTINA\%20DEMARTA\%20TFM\%20final\%20ver sion.pdf

de Villiers, J., \& de Villiers, P. (1973). A cross-sectional study of the acquisition of grammatical morphemes in child speech. Journal of Psycholinguistics Research, 2, 267-278.

Dornyei, Z. (2007). Research methods in applied Linguistics: Quantitative, qualitative, and mixed methodologies. Oxford: Oxford University Press.

Dulay, H., \& Burt, M. (1973). Natural sequence in child second language acquisition. Language Learning, 24(1), 37-53.

Ellis, R. (2010). The study of second language acquisition. Oxford: Oxford University Press.

Ibrahim, A., Nor, M., \& Abu, A. (2013). English grammatical morpheme acquisition order of Malay secondary school students. Jurnal Pendidikan Bitara UPSI, Journal of Sultan Idris Education University, 4, 1-22.

Izumi, E. \& Isahara, H. (2004). Investigation into language learners' acquisition order based on an error analysis of a learner corpus. In L. Anthony, S. Fujita, \& Y. Harada (Ed.), An interactive workshop on language e-learning (pp. 63-71).

Kharrati, A., Ahmadi, S., Mohammaditabar, M., \& Sadighi, F. (2015). The accuracy order of English grammatical morphemes of Iranian EFL learners: An explanation of a universal order. Modern Journal of Language Teaching Methods, 5(4), 43-51.

Khor, S. (2012). A corpus-based study in morpheme acquisition order of young learners of English. Retrieved from Uppsala University, www.divaportal.org/smash/get/diva2:608517/FULLTEXT01.pdf. 
Kim, J. (2001). Grammatical morpheme accuracy order in Korean adult learners of English (Doctoral dissertation). Retrieved from ProQuest Dissertations and Theses database (UMI No. 3039252).

Kown, E. (2005). The "natural order" of morpheme acquisition: A historical survey and discussion of three putative determinants. Teachers College, Columbia University Working Papers in TESOL \& Applied Linguistics, 5(1), 1-21.

Krashen, S. (1977). The monitor model for adult second language performance. In Burt, M., Dulay, H., \& Finocchiaro, M. (Ed.), Viewpoints on English as a second language. New York, Regents Publishing.

Krashen, S. (1981). Second language acquisition and second language learning. New York: Pergamon Press Inc.

Krashen, S. (1982). Principles and practice in second language acquisition. New York: Pergamon Press Inc.

Lightbown, P., \& Spada, N. (2013). How languages are learned (4th ed.). Oxford: Oxford University Press.

Luk, Z., \& Shirai, Y. (2009). Is the acquisition order of grammatical morphemes impervious to L1 knowledge? Evidence from the acquisition of plural -s, articles, and possessive 's. Language Learning, 59(4), 721-754.

Mansouri, F. (Ed.). (2008). Second language acquisition research: Theory construction and testing. Cambridge: Cambridge Scholar Publishing.

Murkami, A., \& T. Alexopoulou. (2016). L1 influence on the acquisition order of English grammatical morphemes: A learner corpus study. Studies in Second Language Acquisition, 38, 365 - 401. doi:10.1017/S0272263115000352

Murakami, A. (2013). Individual variation and the role of L1 in the L2 development of English grammatical morphemes: Insights from learner corpora (Doctoral dissertation, University of Cambridge). Retrieved from https://www.repository.cam.ac.uk/handle/1810/254430.

Pica, T. (1983). Target-like use (TLU) analysis. In Robinson, P. (Ed.), The Routledge encyclopaedia of second language acquisition (pp. 627-628). London and New York: Routledge Taylor and Francis Group.

Schenk, A. \& Choi, W. (2013). Unlocking the secrets of morphosyntactic development by examining acquisition order of disparities in an EFL context. Open Journal of Modern Linguistics, 3(1), 47-57. doi: 10.4236/ojml.2013.31006

Seliger, H., \& Shohamy, E. (2000). (2000): Second language research methods (5th ed.). Oxford: Oxford University Press.

Seog, D. S. Y. (2015). Accuracy order of grammatical morphemes of Korean EFL learners: Disparities among the same L1 groups. Linguistic Research 32 Special Edition, 151-171.

VanPatten, B., \& Benati, A. (2010). Key terms in SLA. London and New York. Continuum International Publishing Group. 


\section{Appendix A.}

Grammaticality Judgement Test

Correct each statement in the spaces provided. ONLY Correct the Underlined words, please.

1- My brother work for organization, its headquarters is located in Dammam.

2- He invite me to cup of tea last night.

3- Now I am go with all of my friend.

4- This is the boys room.

5- sun rise in east.

6- Look! the child is move his both hand.

7- hour ago, I finish interesting game.

8- My brother house was sold to rich man.

9- Yesterday I visit Riyadh by Hamad car.

10- At present, they are stay in USA.

11- Everyday Hind read 3 page in book.

TLU

\begin{tabular}{|l|c|c|l|l|}
\hline \multicolumn{1}{|c|}{ Mrphm } & RCS & OCS & NCS & TLU \\
\hline Prog. & & 3 & & \\
\hline Reg_pst & & 3 & & \\
\hline 3rdps & & 3 & & \\
\hline Pls & & 3 & & \\
\hline poss & & 3 & & \\
\hline Indfa & & 3 & & \\
\hline Indfan & & 3 & & \\
\hline Defar & & 3 & & \\
\hline SUM & & $\mathbf{2 4}$ & & \\
\hline
\end{tabular}

